www.nature.com/pj

\title{
The effect of using the two-step extrusion method on the oxidation induction time value of recycled high density polyethylene
}

\author{
Yan Li, Haiyan Xu and Chifei Wu
}

The two-step extrusion method was used to manufacture pipe-grade high density polyethylene (HDPE) material from recycled HDPE. With the two-step extrusion method, dicumyl peroxide (DCP) can completely react after reactive extrusion without adding antioxidants in the first step, which increased the degree of cross-linking and the molecular weight of the recycled HDPE. Then, adding the antioxidant in the second extrusion step can avoid the conflict between the two additives. As a result, this method improved the oxidation induction time (OIT) and the environmental stress cracking resistance (ESCR) value of HDPE compared with the traditional one-step extrusion method. For both Irganox 1035 and Irganox 300, the OIT using the two-step extrusion method is much higher than that using the one-step method. In addition, introducing carbon black (CB) into the black masterbatch affected the OIT. When the CB content was $0.8 \%$, the OIT was at its maximum value.

Polymer Journal (2012) 44, 421-426; doi:10.1038/pj.2012.9; published online 7 March 2012

Keywords: oxidative induction time (OIT); reactive extrusion; recycled HDPE; two-step extrusion method.

\section{INTRODUCTION}

Plastics account for an increasing fraction of the municipal solid waste worldwide. Low density polyethylene, high density polyethylene (HDPE) and polypropylene are the three largest components of plastic municipal waste. ${ }^{1}$ Recycling contributes to the reduction in resource consumption and pollution. Fortunately, HDPE is an easily recyclable material. When HDPE is broken down for reuse, many materials can be made, such as recycled plastic lumber, toiletry containers, recycling bins, outdoor furniture, liquid containers and pipes. ${ }^{2}$ The typical lifetime requirement for gas and water pipes is $\sim 50$ years, but the pipes can fail in only 1 year because of the environmental stress cracking. ${ }^{3}$ In addition, the oxidation induction time (OIT) is widely used for the determination of the thermal oxidative resistance of polyethylene materials. ${ }^{4}$ The requirement on the OIT in pipe use is that the OIT value must be $>20$ min. $^{5}$ Therefore, both the environmental stress cracking resistance (ESCR) and the OIT of polyethylene are of particular interest to manufacturers and researchers.

Currently, recycled HDPE materials cannot be directly used for producing pipes, because the melt flow index (MFI) of these materials is too high to be extruded for pipes. The cross-linking of PE is an effective way to solve this problem. The most common method of cross-linking is the chemical method, particularly using peroxides as an initiator. Peroxide cross-linking by reactive extrusion is used to cause chain extension or long chain branch, even the cross-linking of HDPE chains, by which the molecular weight (MW) increases, resulting in a lower MFI and improved mechanical properties. ${ }^{6} \mathrm{~A}$ number of additives are also introduced along with the polymer resin before forming the final product, which include stabilizers, ultraviolet-blockers, plasticizers, antioxidants and colorants, and can be used to enhance both the processing and performance characteristics.

The traditional method for manufacturing pipe-grade HDPE material from recycled HDPE is the one-step extrusion method. ${ }^{7}$ With the one-step extrusion method, all the additives are added into the HDPE matrix at the same time, mixed and then reactive extruded. DCP is used as an initiator agent that decomposes into free radicals under thermal treatment to capture the hydrogen molecules of the polyethylene chain. The capture of hydrogen molecules during the macromolecular coupling reaction of radicals forms the desired cross-linked network. Meanwhile, as a free-radical scavenging agent, antioxidants delay the cross-linking of polyolefin to some extent. ${ }^{8}$ Thus, the efficiency of the antioxidants is reduced when simultaneously used in the presence of free radicals. At the same time, the OIT value decreases too. To meet the requirement that OIT $>20 \mathrm{~min}$ for the use of plastics in pipes, the amount of antioxidants used is large, which increases the cost.

This paper presents a new method for processing recycled HDPE into pipe-grade HDPE materials-the two-step extrusion method. In the first step, the initiator and the recycled HDPE matrix are mixed together and processed by reactive extrusion, resulting in the production of the primary HDPE particles. Next, in the second step, 
the antioxidants are added into the primary HDPE particles to perform the second reactive extrusion. This method can improve the OIT, the ESCR and the elongation at break of the recovered HDPE. The recovered HDPE can be used as extruded pipe, reducing the amount of the antioxidants required, and thereby reducing the cost of HDPE pipe materials. In addition, the effects of the carbon black (CB) in the masterbatch on the OIT were studied. With the increasing $\mathrm{CB}$ content, the MFI was nearly constant. When the $\mathrm{CB}$ content was $<0.8 \%$, the OIT increased as the $\mathrm{CB}$ content increased, and when the $\mathrm{CB}$ content was $>0.8 \%$, the OIT decreased with the $\mathrm{CB}$ content. When the $\mathrm{CB}$ content was $0.8 \%$, the OIT attained its maximum value.

\section{EXPERIMENTAL PROCEDURES}

\section{Materials}

The recycled HDPE is obtained from recycled water bottle caps. The MFI $\left(190^{\circ} \mathrm{C}\right.$ per $\left.5 \mathrm{~kg}\right)$ is $5.8 \mathrm{~g}$ per $10 \mathrm{~min}$. The recycled HDPE was obtained from the public markets.

Dicumyl peroxide (DCP), a white crystal, was used as an initiator. The melting point is $41^{\circ} \mathrm{C}$. The density is $1.082 \mathrm{~g} \mathrm{~cm}^{-3}$. The decomposition temperature is $120-125^{\circ} \mathrm{C}$, and the half-life is $1 \mathrm{~min}$ at a temperature of $170^{\circ} \mathrm{C}$. The DCP was obtained from Ciba Australia Limited (Melbourne, Victoria, Australia).

The antioxidants used in this study are Irganox 1035 (3,5-Bis(1,1-dimethylethyl)-4-hydroxybenzenepropanoic acid thiodi-2, 1-ethanediyl ester) and Irganox 300 (1,1'-Thiobis(2-methyl-4-hydroxy-5-tert-butyl)benzene) (Ciba Australia Limited). Their structures are shown in Figure 1. Both of the two antioxidants were obtained from Ciba Australia Limited. The incorporation of $\mathrm{CB}$ into the black masterbatch used in this research was $40 \% \mathrm{w} / \mathrm{w}$.

\section{Preparation of samples}

The samples were prepared according to the formulae in Table 1. The preparation included the one-step extrusion process and the two-step extrusion process, which are shown in Figure 2. The samples were prepared with a twin-screw extrusion using a ZDSK extruder operating at $220^{\circ} \mathrm{C}$ and 300 r.p.m..

\section{Oxidative induction time (OIT)}

The OIT was determined using a Jade DSC (PerkinElmer, Shanghai, China) fitted with an autosampler. A mass of $15.0 \pm 0.5 \mathrm{mg}$ was then placed in an aluminum pan and heated from ambient to $200^{\circ} \mathrm{C}$ under nitrogen at a flow rate of $50 \mathrm{~cm}^{3} \mathrm{~min}^{-1}$. After $5 \mathrm{~min}$ hold at $200{ }^{\circ} \mathrm{C}$, the gas was switched to oxygen at a flow rate of $50 \mathrm{~cm}^{3} \mathrm{~min}^{-1}$. The onset of oxidation (exothermic reaction) was recorded as the OIT value in minutes, and was determined (in accordance with ISO/TR $10837^{9}$ ) as the intercept of the extended baseline and the tangent drawn to the exotherm at the point of the maximum slope.
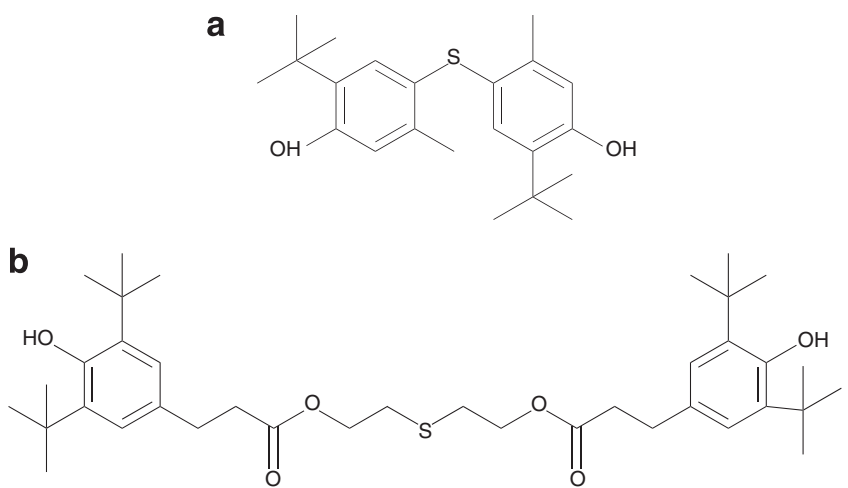

Figure 1 The structure of the antioxidants: (a) Irganox 300 and (b) Irganox 1035.

\section{The ESCR}

The ESCR of polyethylene was measured using the notch constant load test. The experiments were performed following the guidelines of ASTMD5397 at $50{ }^{\circ} \mathrm{C}$ in a temperature bath containing $10 \%$ Igepal (nonylphenyl ether glycol, $\left.\mathrm{C}_{19} \mathrm{H}_{19}-\mathrm{C}_{6} \mathrm{H}_{4}-\mathrm{O}-\left(\mathrm{CH}_{2} \mathrm{CH}_{2} \mathrm{O}\right)_{8}-\mathrm{CH}_{2} \mathrm{CH}_{2} \mathrm{OH}\right)$ solution. A load at $15 \%$ of the yield stress of the material was used to ensure that fracture occurred in the brittle failure region. The dogbone-shaped samples were cut from plates of polymer made by compression molding at $180 \pm 5^{\circ} \mathrm{C}$.

\section{RESULTS AND DISCUSSION}

\section{The effects of different DCP content}

Traditionally, the evaluation of the MFI and the mechanical properties of the recycled material were the properties that are determined in the specification sheets of the final material; however, the specification of such macroscopic properties may be misleading in terms of assessing the performance of the recycled products in new applications. ${ }^{10-12}$

\section{Table 1 Formula of the samples}

\begin{tabular}{|c|c|c|c|c|c|c|}
\hline Sample & $\begin{array}{l}\text { Recycled } \\
\text { HDPE(\%) }\end{array}$ & $\begin{array}{c}\angle D P E \\
(\%)\end{array}$ & $\begin{array}{c}\text { Masterbatch } \\
\text { (\%) }\end{array}$ & $\begin{array}{c}\text { Antioxidants } \\
\text { (\%) }\end{array}$ & $D C P(\%)$ & Oil(\%) \\
\hline PE1 & 92.3 & 5 & 1 & 0.2 (Inganox 1035) & 0 & 1.5 \\
\hline PE2 & 92.25 & 5 & 1 & 0.2 (Inganox 1035) & 0.05 & 1.5 \\
\hline PE3 & 92.2 & 5 & 1 & 0.2 (Inganox 1035) & 0.15 & 1.5 \\
\hline PE4 & 92.15 & 5 & 1 & 0.2 (Inganox 1035) & 0.20 & 1.5 \\
\hline PE5 & 92.12 & 5 & 1 & 0.2 (Inganox 1035) & 0.23 & 1.5 \\
\hline PE6 & 92.25 & 5 & 1 & 0.1 (Inganox 1035) & 0.15 & 1.5 \\
\hline PE7 & 92.2 & 5 & 1 & 0.15 (Inganox 1035) & 0.15 & 1.5 \\
\hline PE8 & 92.15 & 5 & 1 & 0.2 (Inganox 1035) & 0.15 & 1.5 \\
\hline PE9 & 92.1 & 5 & 1 & 0.25 (Inganox 1035) & 0.15 & 1.5 \\
\hline PE10 & 92.05 & 5 & 1 & 0.3 (Inganox 1035) & 0.15 & 1.5 \\
\hline PE11 & 92.25 & 5 & 1 & 0.1 (Inganox 300) & 0.15 & 1.5 \\
\hline PE12 & 92.2 & 5 & 1 & 0.15 (Inganox 300) & 0.15 & 1.5 \\
\hline PE13 & 92.15 & 5 & 1 & 0.20 (Inganox 300) & 0.15 & 1.5 \\
\hline PE14 & 92.1 & 5 & 1 & 0.25 (Inganox 300) & 0.15 & 1.5 \\
\hline PE15 & 92.2 & 5 & 1 & 0.2 (Inganox 1035) & 0.15 & 1.5 \\
\hline PE16 & 91.2 & 5 & 2 & 0.2 (Inganox 1035) & 0.15 & 1.5 \\
\hline PE17 & 90.2 & 5 & 3 & 0.2 (Inganox 1035) & 0.15 & 1.5 \\
\hline
\end{tabular}

Abbreviations: DCP, dicumyl peroxide; HDPE, high density polyethylene; LDPE, low density polyethylene; $\mathrm{PE}$, polyethylene.

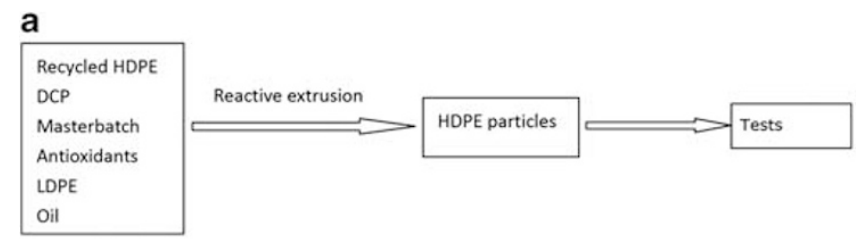

b

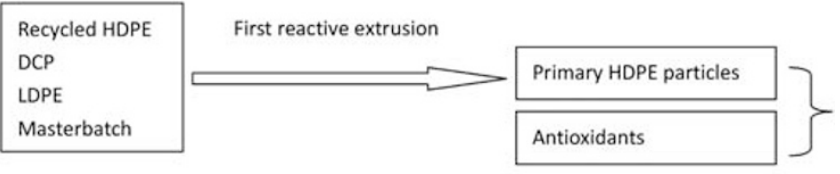

Second reactive extrusion

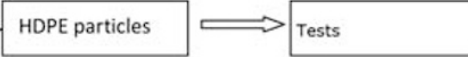

Figure 2 The experimental processes. (a) The one-step extrusion process and (b) the two-step extrusion process. 


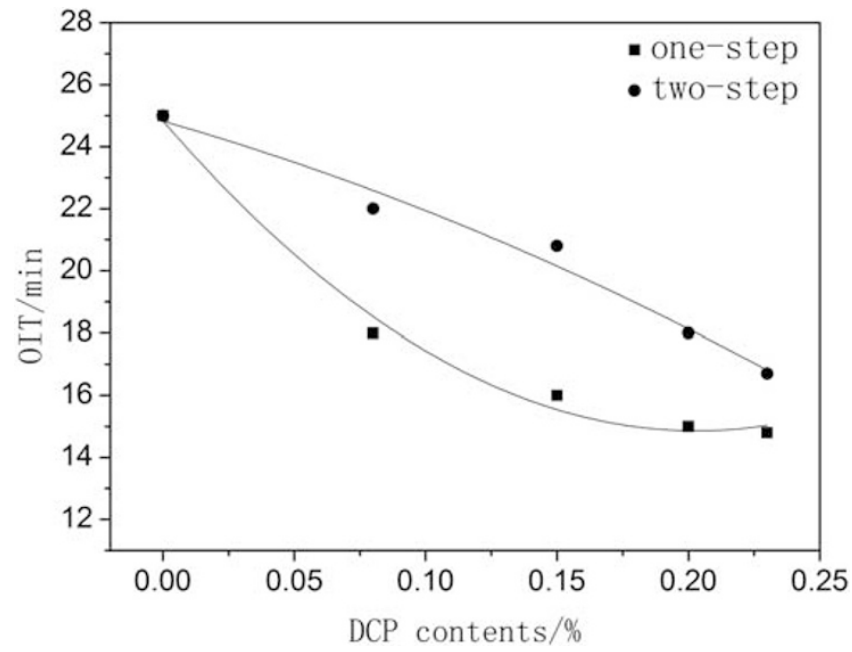

Figure 3 The OIT data of samples PE1-PE5 expressed as the percentage of DCP (\%). The antioxidant (Irganox 1035) content is $0.2 \%$.

In the field of polymer recycling, the OIT is used for the determination of the residual stabilizing system in recycled resins, which is extremely important for evaluating the need for further stabilization during the mechanical recycling process to guarantee long-term stability. ${ }^{13-15}$

The OIT results of samples PE1-PE5 as a function of the percentage of DCP in the samples is shown in Figure 3. The first important feature is that the OIT value decreased after adding DCP, both with the one-step and the two-step extrusion methods. However, the value is higher with the two-step extrusion method than that with the onestep extrusion method. As the DCP content increases, the OIT has a decreasing trend. The DCP used as an initiation agent decompose into free radicals under thermal treatment, and these free radicals capture the hydrogen molecules of the polyethylene chain. This hydrogen capture leads to the formation of the cross-linked network in the macromolecular coupling reaction of the radicals. ${ }^{16,17}$ However, at the same time, the antioxidant acts as a free-radical scavenging agent, which delays the cross-linking of the polyolefin to some extent, and the effect of the antioxidants is reduced. The effect of the DCP and the antioxidants are, to some degree, in conflict with one another. The two-step extrusion method can overcome this shortcoming. In the first step of the two-step extrusion method, the free radicals from the DCP can capture the hydrogen molecules to form the cross-linked network of the recycled HDPE. The efficiency of the DCP is higher without the opposing effect of the antioxidant. At the same time, because most of the DCP is consumed in the first extrusion step, conflict with the antioxidant is minimized. Thus, the efficiency of the antioxidant increases, leading to the increase of the OIT.

The MFI data of samples PE1-PE5 expressed as percentage of DCP (\%) are shown in Figure 4. After adding the DCP, the MFI significantly decreases. The MFI is determined to obtain an indirect measurement of the changes in the average molecular weight MW and the MW distribution of the sample. The decrease of the MFI indicates that cross-linking formed in both systems results in the increase of the MW. When no DCP was added, the MFI with the two-step extrusion method is slightly higher than that with one-step extrusion method. The HDPE was extruded two times with two-step extrusion method, which resulted in a higher degree of the degradation. However, after adding DCP, the MFI of the two-step method is lower than that of the

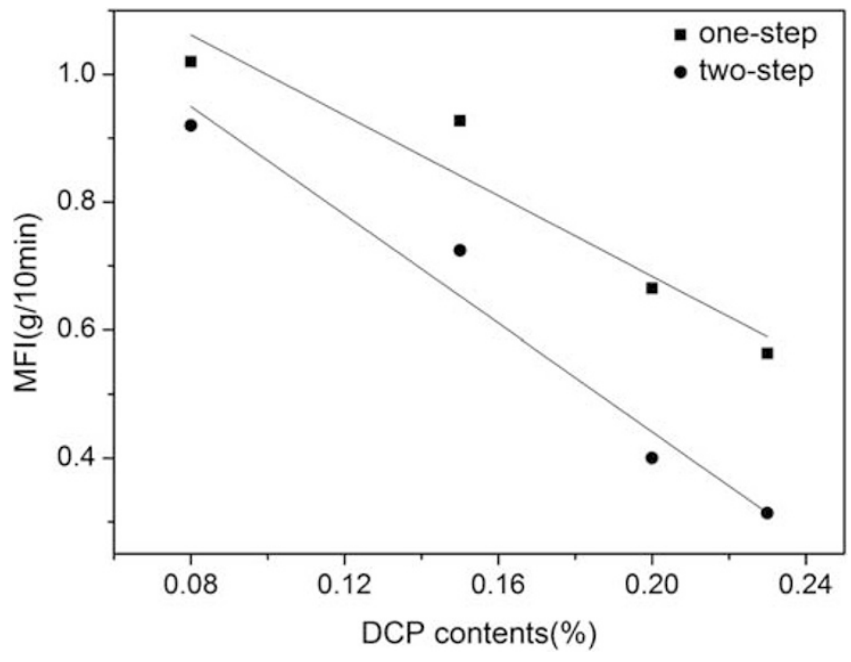

Figure 4 The MFI data of samples PE1-PE5 expressed as the percentage of DCP (\%). The antioxidant (Irganox 1035) content is $0.2 \%$.

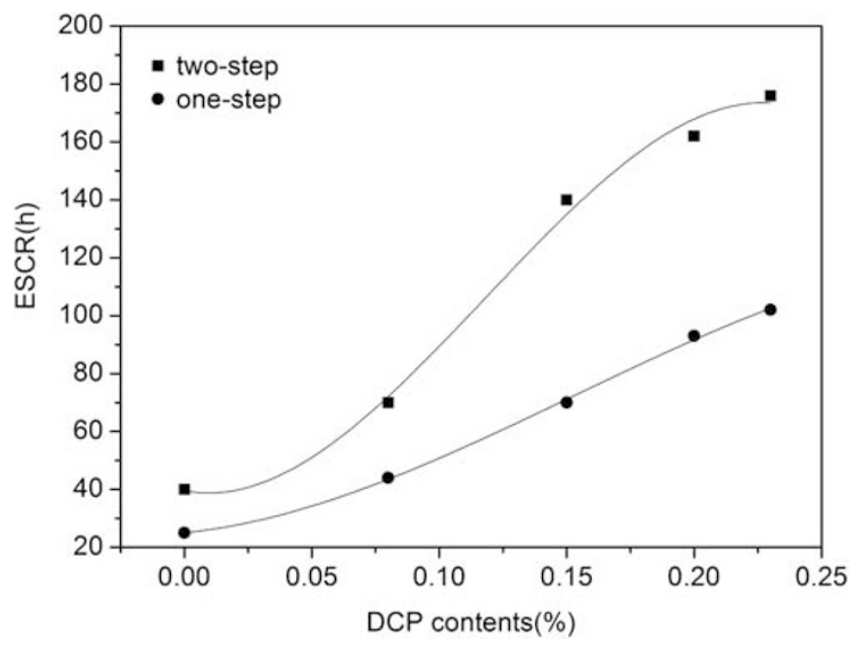

Figure 5 The relationship between the DCP content and the ESCR value of the samples PE1-PE5 from both the one-step and two-step extrusion methods.

one-step method. Without the antioxidants, the HDPE can react more completely in the first extrusion step, resulting in an improved degree of cross-linking.

The relationship between the DCP contents and the ESCR of the samples PE1-PE5 both with one-step extrusion and two-step extrusion is shown in Figure 5. As the DCP content increases, the ESCR value increases as well, both for the one-step extrusion and the two-step extrusion. In addition, the ESCR value with the two-step extrusion method is higher than that with the one-step method. The environmental stress cracking is due to brittle fracture. ${ }^{18}$ Research has shown that the ESCR of HDPE increases with increasing MW. ${ }^{19-21}$ When the DCP content increases, both the degree of cross-linking and the MW increase. A high MW indicates the presence of long polymer chains that can crystallize into two or more lamellae and form interlamellar connections that improve the ESCR. The relationship between the ESCR and the OIT of samples PE1-PE5 both in the one-step and the two-step methods are shown in Figure 6. The ESCR 


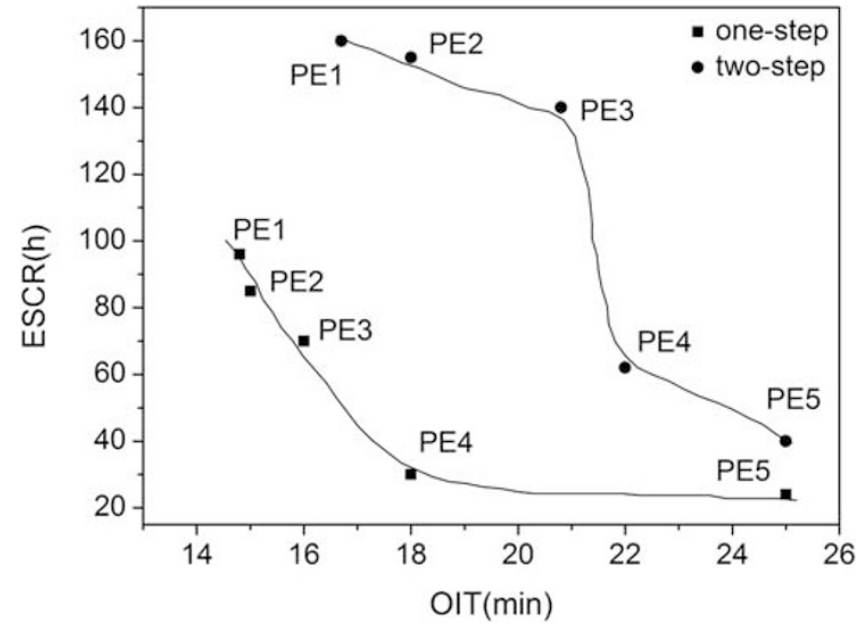

Figure 6 The relationship between the ESCR and the OIT value of the samples PE1-PE5 from both the one-step and two-step extrusion methods.

and OIT are found to have opposite behavior as a function of the DCP content; as the DCP contents increased, the ESCR value increased, but the OIT decreased. Thus, the DCP content should not be arbitrarily increased to increase the ESCR value. Both the OIT and the ESCR should be taken into consideration to determine the amount of DCP to add.

Table 2 shows the mechanical properties of sample PE3 processed using both the one-step and two-step extrusion methods. The data shows that the elongation at break of the sample is higher with the two-step extrusion method. The elongation at break is often used as a key toughness indicator of polymer aging. Because the elongation at break of the samples increased with the two-step extrusion method, using the two-step method increases the toughness of the material. Meanwhile, the other mechanical properties of samples from the twostep extrusion method were nearly identical with those from the onestep extrusion method, which demonstrates the processing stability of the materials.

\section{The effect of different types of antioxidants on the OIT}

Figure 7 shows the OIT curves of samples PE7-PE14. When the DCP is maintained at a content of $0.15 \%$ for Irgranox 1035 and Irganox 300 , both the OIT in the one-step and two-step methods increased as the antioxidant content increased. The addition of the antioxidant inhibits the oxidative degradation of the polymer. If the concentration of antioxidant is increased, the onset of the oxidation is delayed and an increase in the OIT is observed. When the antioxidant content was constant, the OIT results obtained from samples using the two-step extrusion method were higher than that from samples using the onestep extrusion method, which fully illustrates the significance of the two-step extrusion method on the OIT. If the desired OIT is $20 \mathrm{~min}$, the amount of Irganox 1035 needed in the one-step method is $0.28 \%$, whereas it is only $0.2 \%$ in the two-step method.

Figure 7 also shows that when the antioxidant content is the same, the OIT values of Irganox 300 are higher than that of Irganox 1035, both in the one-step and the two-step extrusion methods, which illustrates the higher antioxidation efficiency of Irganox 300 versus Irganox 1035. It is believed that the key role of the hindered phenol antioxidants is its reactive hydroxyl. The reactivity of the hydroxyl and the radical is affected by its o- $\mathrm{R}$ group's space. If the $\mathrm{R}$ group is large, the obstacle of the group is large, which results in the small reactivity
Table 2 Mechanical properties of the sample PE3

\begin{tabular}{ccccccc}
\hline $\begin{array}{c}\text { Impact } \\
(\text { notch)/ } \\
M P a\end{array}$ & $\begin{array}{c}\text { Yield } \\
\text { strength/ } \\
M P a\end{array}$ & $\begin{array}{c}\text { Breaking } \\
\text { strength/ }\end{array}$ & $\begin{array}{c}\text { Breaking } \\
\text { elongation } \\
\text { MPa }\end{array}$ & $\begin{array}{c}\text { Bending } \\
\text { strength/ }\end{array}$ & $\begin{array}{c}\text { Bending } \\
M P a\end{array}$ & modulus \\
\hline One-step & $50.7 \pm 1.2$ & $23.8 \pm 0.3$ & $2.4 \pm 0.1$ & $101 \pm 22.5$ & $20.0 \pm 0.8$ & $475 \pm 8.7$ \\
Two-step & $49.1 \pm 2.1$ & $22.0 \pm 0.8$ & $2.2 \pm 0.1$ & $179 \pm 29.5$ & $18.2 \pm 0.3$ & $430 \pm 8.1$ \\
\hline Abbreviation: Mpa, Mega Pascal. & & & &
\end{tabular}

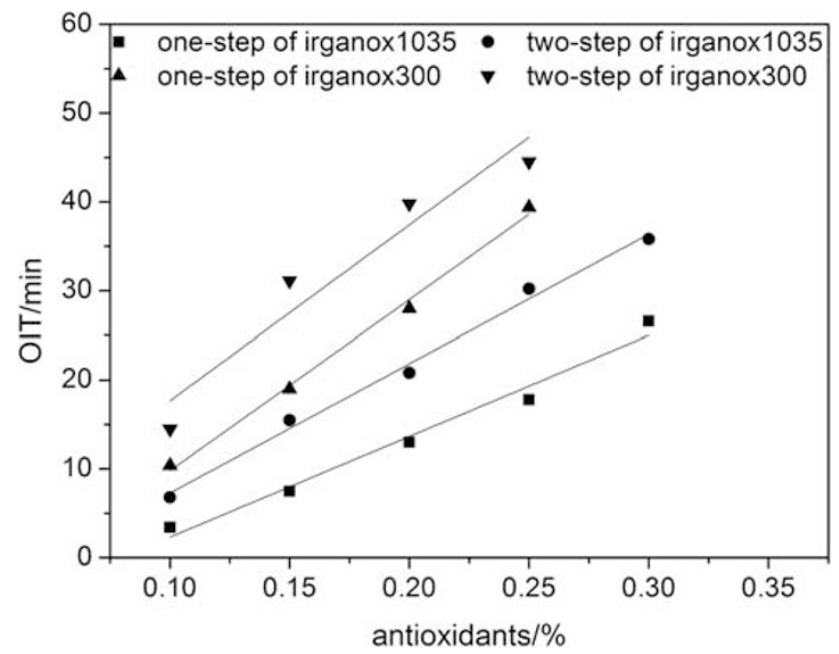

Figure 7 The OIT data of samples PE7-PE14 expressed as the content of antioxidant in the sample. The DCP content is $0.15 \%$.

of the hydroxyl and the radical. An antioxidant with a small o-R group reacts the fastest, followed by the two small groups of the antioxidant, a large $\mathrm{R}$ group and finally two $\mathrm{R}$ groups, which respond the slowest. ${ }^{22}$ For the thio-hindered phenolic antioxidants, the hydroxyl can capture the polymer peroxide radical (ROO) to generate hydrogen peroxide $(\mathrm{ROOH})$. Meanwhile, the sulfur atom can decompose the ROOH into an alcohol, leading to stabilization of the polymer. Thus, the interval time between the two steps is critical for the efficiency of the antioxidant. From the structure of the two antioxidants (see Figure 1), it can be observed that Irganox 1035 has two large R groups, whereas there is only one large group in Irganox 300 , so the steric resistance of Irganox 300 is much smaller than that of Irganox 1035. Thus, the interval time of the Irganox 300 is much shorter, which results in a higher efficiency for the Irganox 300.

Figure 8 shows the MFI data as a function of the content of Irganox 1035 , both in the one-step and two-step methods. It reflects the influence of different antioxidants on the MFI. For the same antioxidant, as the antioxidant content increased, the MFI remains nearly constant. However, the MFI from the one-step extrusion method is higher than that from the two-step method, both for Irganox 1035 and Irganox 300, which is in agreement with the above mentioned arguments.

\section{The effects of the masterbatch on the OIT}

It has been established that $\mathrm{CB}$ has a significant role in retarding the thermal oxidation of polymeric materials, either by acting as a mild thermal antioxidant or by influencing the activity of other antioxidants. $^{23-28}$ Figure 9 shows the MFI and the OIT data of samples PE15-PE17 expressed as the black masterbatch content using 


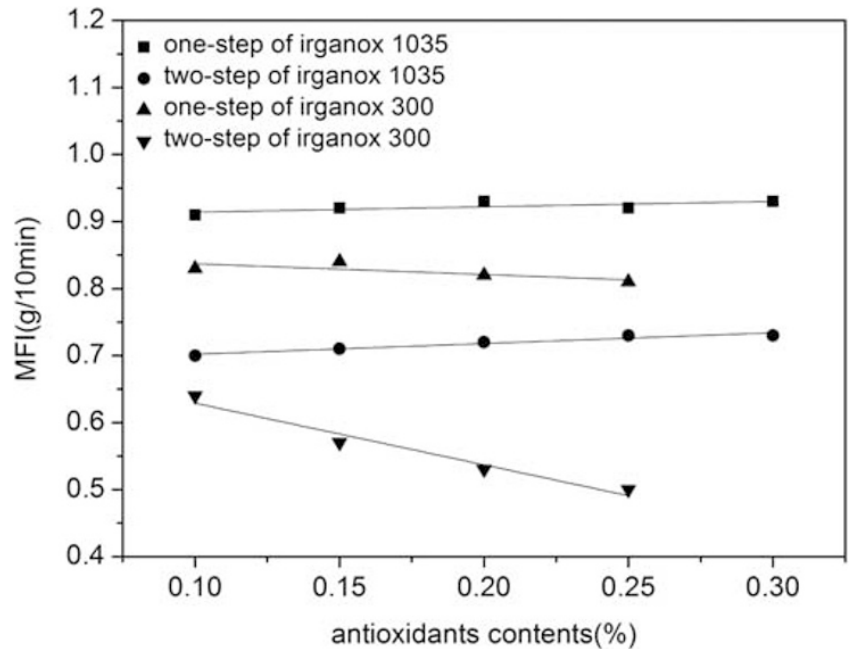

Figure 8 The MFI data expressed as the content of Irganox 1035 in samples from both the one-step and two-step extrusion methods.

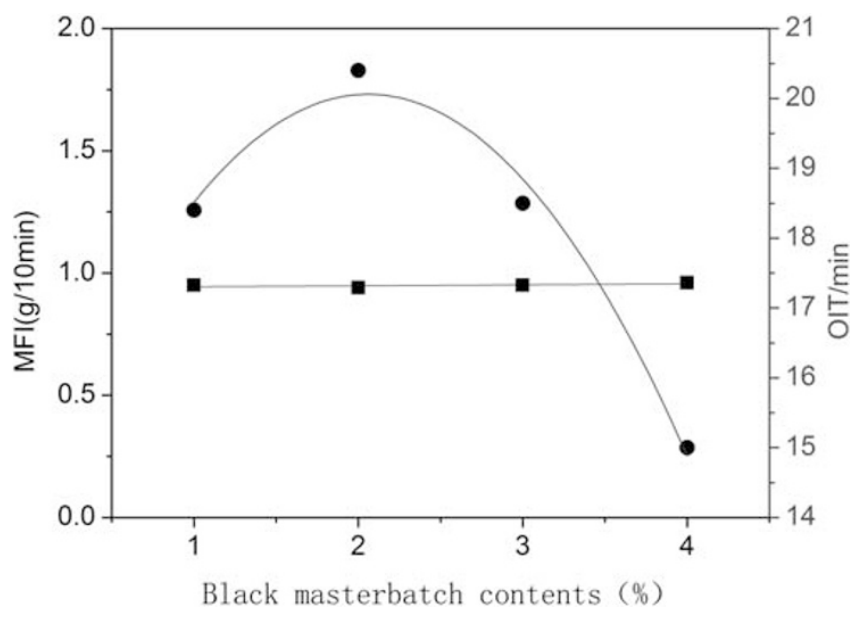

Figure 9 The MFI and OIT data of samples PE15-PE17 expressed as the black masterbatch content for samples from the two-step process. The DCP content is $0.15 \%$ and the Irganox 1035 content is $0.2 \%$.

the two-step extrusion method. When both the DCP and antioxidant content remain constant, as the $\mathrm{CB}$ content increased, the MFI remains nearly constant. When the $\mathrm{CB}$ content was $<0.8 \%$ the OIT increased as the $\mathrm{CB}$ content increased, and when the $\mathrm{CB}$ content was $>0.8 \%$ the OIT decreased as the $\mathrm{CB}$ content increased. When the $\mathrm{CB}$ content was $0.8 \%$, the OIT had the maximum value. It is known that $\mathrm{CB}$ has synergy with the hindered phenolic antioxidants. It is therefore expected that the addition of $\mathrm{CB}$ to a polymeric formulation will, in general, increase the observed OIT. When the CB content is small, the antioxidants and the $\mathrm{CB}$ particles are nearly uniformly dispersed, which can optimize the effect of the synergy. However, when the $\mathrm{CB}$ content is large, it is expected to interfere with the migration of the antioxidant and decrease, or even eliminate, any synergy that would occur. In addition, the CB particles absorb antioxidant molecules onto their surfaces, thereby reducing the mobility of the antioxidant, which would also decrease the efficiency

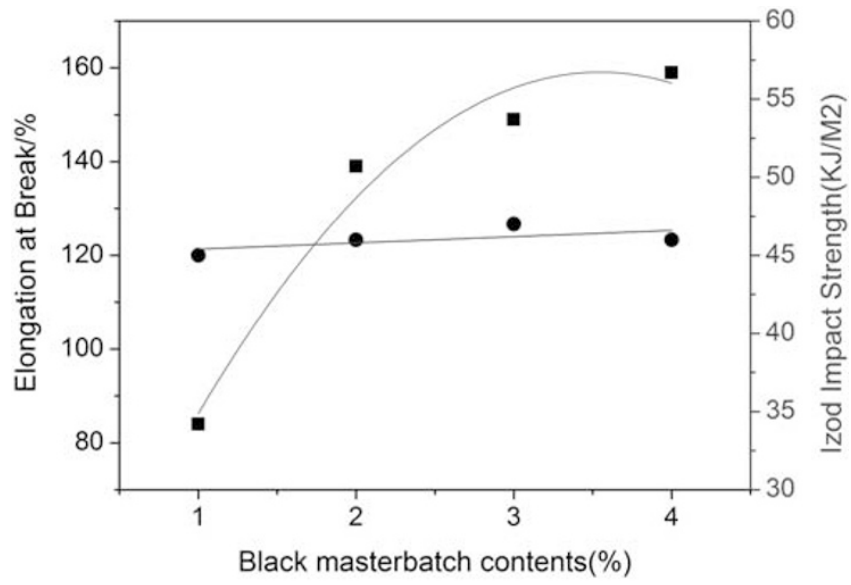

Figure 10 The elongation at break and the Izod impact strength versus the black masterbatch content of PE15-PE17 samples from the two-step method.

of the antioxidants. Thus, the optimum effective concentration of the $\mathrm{CB}$ content is $0.8 \% \mathrm{w} / \mathrm{w}$, where the synergy between the $\mathrm{CB}$ and the antioxidants is the highest.

The elongation at break is often used as a key toughness indicator of polymer aging. Figure 10 shows the change of the elongation trends as a function of the $\mathrm{CB}$ content of the sample. The figure shows that the elongation at break increases with the CB content of the samples, which indicates that the toughness of the samples increases gradually as the CB content increases. The impact properties of the materials can be used to evaluate the impact resistance, where aging can affect the impact of material properties. Owing to the strong toughness, the impact resistance data of HDPE are not thrust spline data. Figure 10 shows that the impact strength changes little, which can be observed as basically not changing, with a change in the $\mathrm{CB}$ content. This indicates that the impact of $\mathrm{CB}$ on the properties of the material is very small.

\section{CONCLUSION}

The effect of the two-step extrusion method on the OIT of recycled HDPE converted to pipe-grade HDPE material was demonstrated in this study. In the method of two-step extrusion, without adding antioxidants in the first step, DCP can react more completely after reactive extrusion, which increased the cross-linking degree of the recycled HDPE. The subsequent addition of the antioxidant in the second extrusion step avoids the opposing effects of the two additives. As a result, this two-step method improved the oxidation inducing time (OIT) and the ESCR value of HDPE compared with the traditional one-step extrusion method. With the use of both Irganox 1035 and Irganox 300, the OIT in the two-step extrusion method is much higher than the OIT in the one-step extrusion method. For both the one-step extrusion method and the two-step extrusion method, the OIT value with the use of Irganox 300 was higher than that obtained with the use of Irganox 1035. In addition, the amount of $\mathrm{CB}$ in the black masterbatch had an effect on the OIT. As the CB content increased, the MFI was nearly constant. When the $\mathrm{CB}$ content was $<0.8 \%$, the OIT increased as the $\mathrm{CB}$ content increased, and when the $\mathrm{CB}$ content was $>0.8 \%$, the OIT decreased as the $\mathrm{CB}$ content increased. The OIT reached the maximum value with a $\mathrm{CB}$ content of $0.8 \%$. 
1 Luo, H. Plastic Handbook (Guangdong Science and Technology Publishing Press, Guangzhou, 2010).

2 Vilaplana, F. \& Karlsson, S. Quality concepts for the improved use of recycled polymeric materials: a review. Macro. Mater. Eng. 293, 274-297 (2008).

3 Brostow, W. \& Corneliussen, R. D. Failure of Plastics (Hanser Publishers, New York, 1986).

4 Celina, M., Gillen, K. T. \& Assink, R. A. Accelerated aging and lifetime prediction: review of non-Arrhenius behaviours due to two competing processes. J. Polym. Degrad. Stab. 90, 395-404 (2005).

5 Sun, X. Polyolefin Pipe (Chemical Industry Press, Publishing Center of Materials Science and Engineering, Beijing, 2002).

6 Anbarasan, R., Babot, O. \& Maillard, B. Crosslinking of high-density polyethylene in the presence of organic peroxides. J. Appl. Polym. Sci. 93, 75 (2004).

7 Wu, CF. A Method for the Regeneration of HDPE Pipe Particles and Their Manufacturing Methods. CN 101805472 A (China, 2010).

8 Allen, N. S., Hoang, E., Liauw, C. M., Edge, M. \& Fontan, E. Influence of processing aids on the thermal and photostabilisation of HDPE with antioxidant blends. J. Polym. Degrad. Stab. 72, 367-76 (2001).

9 Determination of the thermal stability of polyethylene (PE) for using as pipes and fittings (ISO/TR10837).

$10 \mathrm{Karlsson}, \mathrm{S}$. Recycled polyolefins. material properties and means for quality determination. Adv. Polym. Sci. 169, 201-230 (2004).

11 Boldizar, A. \& Moller, K. Degradation of ABS during repeated processing and accelerated ageing. J. Polym. Degrad. Stab. 81, 359-366 (2003).

12 Vilaplana, F., Ribes-Greus, A. \& Karlsson, S. Analytical strategies for the quality assessment of recycled high-impact polystyrene: a combination of thermal analysis, vibrational spectroscopy and chromatography. Acta Chim Analtica. 604, 18 (2007).

13 Vilaplana, F., Ribes-Greus, A. \& Karlsson, S. Degradation of recycled high-impact polystyrene simulation by reprocessing and thermo-oxidation. J. Polym. Degrad. Stab. 91, 2163 (2006).

14 Camacho, W. \& Karlsson, S. Assessment of thermal and thermo-oxidative stability of multi-extruded recycled PP, HDPE and a blend thereof. J. Polym. Degrad. Stab. 78, 385 (2002).
15 Kyriakou, S. A., Statherpoulos, M., Parissakis, G. K., Papaspyrides, C. D. \& Kartalis, C. N. Oxidative induction time method based on thermogravimetry for monitoring the restabilization of post-use LDPE. J. Polym. Degrad. Stab. 66, 49 (1999).

16 Anbarasan, R., Babot, O. \& Maillard, B. Crosslinking of high-density polyethylene in the presence of organic peroxides. J. Appl. Polym. Sci. 93, 75-81 (2004).

17 Hoang*, E. M. \& Lowe, D. Lifetime prediction of a blue PE100 waterpipe. J. Polym. Degrad. Stab. 93, 1496-1503 (2008).

18 Lustiger, A. \& Markham, R. L. Importance of tie molecules in preventing polyethylene fracture under long-term loading conditions. Polymer 24, 1647-1654 (1983).

19 Cheng, J. J., Polak, M. A. \& Penlidis, A. Phase interconnectivity and environmental stress cracking resistance of polyethylene: a crystalline phase investigation. J. Macro. Sci. Part A 46, 572-583 (2009).

20 Huang, Y. \& Brown, N. The effect of molecular weight on slow crack growth in linear polyethylene homopolymers. J. Mater. Sci. 23, 3648-3655 (1988).

21 Yeh, J. T. \& Runt, J. Fatigue crack propagation in high-density polyethylene. J. Polym Part B: Sci. Pol. Phys. 29, 371-388 (1991)

22 Wang, G. \& Wang, J. Mechanism and research on antioxidant. Synth. Mater. agi. appl. 35 (2006).

23 Hawkins, W. L. Carbon black as a catalyst in the oxidation of antioxidants. J. Polym Sci. 62, 106-107 (1962)

24 Hawkins, W. L. Recent advances in mechanisms for the stabilization of polyolefins J. Polym. Sci. 57, 319-28 (1976).

25 Hawkins, W. L., Matreyek, W. \& Winslow, F. H. The effect of carbon black on thermal antioxidants for polyethylene. J. Polym. Sci. 41, 1-11 (1959).

26 Mwila, J., Miraftab, M. \& Horrocks, A. R. The influence of carbon black on properties of orientated polypropylene 2. Thermal and photo degradation. J. Polym. Degrad. Stab. 44, 351 (1994).

27 Foster, G., Pospisil, J. \& Klemchuk, P. P. Oxidation and Inhibition in Organic Materials Vol. 2 (CRC Press, Boca Raton, 1990).

28 Kovacs, E. \& Wolkober, Z. The effect of the chemical and physical properties of carbon black on the thermal and photo oxidation of polyethylene. J. Polym. Sci. Pol. Sym. Serv. 57, 171-80 (1976). 